\title{
Determination of Asperulosidic Acid and Deacetylasperulosidic Acid in Rat Plasma After Administration of Morinda citrifolia Juice
}

\author{
Mitsuhiro WADA ${ }^{* 1,2}$, Yutaro YAMASAKI ${ }^{2}$, Shinichi NAKAMURA ${ }^{1}$, Makoto TAKADA $^{3}$, Shigeru \\ KAWAKAMI $^{2}$, Kenichiro NAKASHIMA ${ }^{3}$ \\ ${ }^{1}$ School of Pharmaceutical Sciences, Kyushu University of Health and Welfare, 1714-1 Yoshino-machi, \\ Nobeoka 882-8508, Japan \\ ${ }^{2}$ Graduate School of Biomedical Sciences, Course of Pharmaceutical Sciences, Nagasaki University, 1-14 Bunkyo-machi, \\ Nagasaki 852-8521, Japan \\ ${ }^{3}$ Fuculty of Pharmaceutical Sciences, Nagasaki International University, 2825-7 Huis Ten Bosch, Sasebo 859-3298, Japan
}

\begin{abstract}
Determination of asperulosidic acid (AA) and deacetylasperulosidic acid (DAA) in rat plasma after administration of Morinda citrifolia juice by HPLC-UV detection was described. Deproteinized rat plasma $(200 \mu \mathrm{L})$ with MeOH for the HPLC analysis was injected. AA and DAA was separated on $\mathrm{ZIC}^{\circledR}$-HILIC $(250 \times 4.6 \mathrm{~mm}$, i.d., $5 \mu \mathrm{m})$ with a mixture of $\mathrm{CH}_{3} \mathrm{CN} / \mathrm{MeOH} / 0.1 \%$ formic acid aqueous solution $(=70: 25: 5, \mathrm{v} / \mathrm{v} / \mathrm{v})$ at a flow rate of $0.75 \mathrm{~mL} / \mathrm{min}$. The absorbance of eluate was monitored at 235 $\mathrm{nm}$. Under this condition, the separation of AA and DAA was achieved within $25 \mathrm{~min}$. The calibration curves using plasma spiked with standards indicated good linearity $(r \geq 0.996)$ in the range of $0.8-20 \mu \mathrm{g} / \mathrm{mL}$ for AA and $4-100 \mu \mathrm{g} / \mathrm{mL}$ for DAA, respectively. The limits of quantitation for AA and DAA at a signal-to-noise ratio of 10 were 0.3 and $1.1 \mu \mathrm{g} / \mathrm{mL}$, respectively. The validation parameters of the method such as recovery (94.9-101.7\%), precisions (less than $7.1 \%$ for intra-day and less than $9.8 \%$ for inter-day) and accuracy (95.0-101.7\%) were acceptable. The analytes in rat plasma were stable after three freeze-thaw cycles or storage at room temperature for up to $6 \mathrm{~h}$. Furthermore, monitoring of AA and DAA after administration of the Morinda citrifolia juice in which AA and DAA were determined, was successfully demonstrated. This is the first report to determine AA and DAA in rat plasma after administration of Morinda citrifolia juice.
\end{abstract}

Keywords: Asperulosidic acid; Deacetylasperulosidic acid; Morinda citrifolia (Noni)

\section{Introduction}

Morinda citrifolia (call as Noni) is native from Southeast Asia to Australia and has been used for centuries as a food or medicinal plant [1]. Most Morinda citrifolia fruit is consumed as juice and its tea and supplement are also commercially available. The main proven functionalities of Morinda citrifolia are related to the control of several diseases. Basic research and limited experiments with animals have shown that Morinda citrifolia has anti-microbial [2], anti-cancer [3-6], antioxidant [7-9], anti-inflammatory [10] and anti-cardiovascular activities
[11]. Ingredients such as amino acids, anthraquinones, coumarins, fatty acids, flavonoids and iridoids which might contribute to the bioactivities of Morinda citrifolia, have been identified [1,12]. However, a few determination methods for these in Morinda citrifolia product has been established [7,12].

Among them, iridoid derivatives focus on due to their beneficial effects (anti-microbial or anti-inflammatory activities) $[10,13]$. Major species of the iridoid derivatives in Morinda citrifolia identified were asperulosidic acid (AA) and deacetylasperulosidic acid (DAA) (Fig. 1)

Received: 20 August 2016

Accepted: 13 September 2016

J-STAGE Advance Published: 27 September 2016

DOI: 10.15583/jpchrom.2016.014 
$[10,13,14]$. Deng et al., developed an HPLC-photodiode array (HPLC-PDA) method for the determination of AA and DAA in Morinda citrifolia [14]. However, no method for determination of them in biological sample after administration of Morinda citrifolia product has been reported.

In this study, an HPLC method for determination of AA and DAA in rat plasma was established. Method validation of the proposed method and stability of analytes in plasma was also evaluated. Furthermore, monitoring of AA and DAA after administration of the Morinda citrifolia juice in which AA and DAA was determined, was demonstrated. This is the first report to determine AA and DAA in rat plasma after administration of Morinda citrifolia product.



Asperulosidic acid (AA)

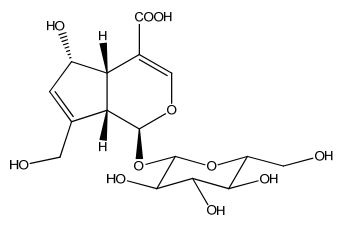

Deacetylasperulosidic acid (DAA)
Fig. 1. Chemical structures of AA and DAA.

\section{Experiments}

\subsection{Chemicals}

AA and DAA were purchased from Sigma-Aldrich Co. (St. Louis, MO, USA). $\mathrm{CH}_{3} \mathrm{CN}, \mathrm{MeOH}$, formic acid and ethyl carbamate from Wako Pure Chem. Co. (Osaka, Japan) were used. Morinda citrifolia juices were kindly gifted from Dr. Nishigaki (M\&K Laboratories, Nagano, Japan). Distilled water was passed through a Pure Line WL21P system (Yamato Scientific Co., Tokyo, Japan). All other chemicals were of analytical grade. A standard stock solutions $(10 \mathrm{mg} / \mathrm{mL})$ of $\mathrm{AA}$ and $\mathrm{DAA}$ in $\mathrm{MeOH}$ was prepared and storing at $4^{\circ} \mathrm{C}$ until analysis. For the evaluation of method validation, the stock solution was appropriately diluted with $\mathrm{MeOH}$.

\subsection{Sample preparations}

Two-hundred micro-liter of rat plasma were added to 400 $\mu \mathrm{L}$ of $\mathrm{MeOH}$ for deproteinization, and then centrifuged $(2000 \mathrm{~g})$ at $4^{\circ} \mathrm{C}$ for $15 \mathrm{~min}$. After filtration with the membrane filter $(0.45 \mu \mathrm{m})$, the sample supernatant was injected into the HPLC system.

For determination of AA and DAA in Morinda citrifolia juices, the sample diluted 10 times with $\mathrm{MeOH}$ was vortex-mixed for $1 \mathrm{~min}$ and centrifuged $(2000 \mathrm{~g})$ at $10^{\circ} \mathrm{C}$ for $10 \mathrm{~min}$. The filtered supernatant with a membrane filter $(0.45 \mu \mathrm{m})$ was appropriately diluted with $\mathrm{MeOH}$.

\subsection{HPLC conditions}

The HPLC system for the determination of AA and DAA consisted of an LC-10AD $\mathrm{VP}_{\mathrm{VP}}$ chromatographic pump (Shimadzu, Kyoto, Japan), a rheodyne 7125 injector (Sigma-Aldrich Co.) with a $20 \mu \mathrm{L}$ of sample loop, a ZIC ${ }^{\circledR}$-HILIC separation column $(250 \times 4.6 \mathrm{~mm}$, i.d., $5 \mu \mathrm{m}$, Sigma-Aldrich Co.) and an SPD-10AV spectrophotometric detector (Shimadzu). The mixture of $\mathrm{CH}_{3} \mathrm{CN}$ and $0.1 \%$ formic acid aqueous solution $(87: 13, \mathrm{v} / \mathrm{v})$ flowed at 0.5 $\mathrm{mL} / \mathrm{min}$, and $\mathrm{CH}_{3} \mathrm{CN}, \mathrm{MeOH}$ and $5 \%$ formic acid aqueous solution $(70: 25: 5, \mathrm{v} / \mathrm{v} / \mathrm{v})$ flowed at $0.75 \mathrm{~mL} / \mathrm{min}$ was used for both Morinda citrifolia juice and rat plasma. The wavelength at $235 \mathrm{~nm}$ was used to monitor the eluate.

To identify AA and DAA in plasma, Waters Alliance 2695 separation module with 2996 photodiode array detector (Waters, Milford, MA, USA) was used. The absorption spectra ranging from 200 to $400 \mathrm{~nm}$ between standard and the observed sample peak were checked.

\subsection{Method validation}

The method was validated according to the US Food and Drug Administration Guideline for Bioanalytical Methods as detailed below [15]. Calibration curves for AA and DAA were prepared using rat plasma spiked with standard ranging from 0.8 to $20 \mu \mathrm{g} / \mathrm{mL}$ for $\mathrm{AA}$, and from 4 to 100 $\mu \mathrm{g} / \mathrm{mL}$ for DAA. The limits of detection (LOD) and quantification (LOQ) were defined as the concentration of analytes giving a signal to noise $(\mathrm{S} / \mathrm{N})$ ratio of 3 and 10 , respectively. The method's recovery, accuracy and precisions were assessed by analyzing the plasma samples spiked with three concentrations $(0.8,3$ and $20 \mu \mathrm{g} / \mathrm{mL}$ for AA and 4, 15 and $100 \mu \mathrm{g} / \mathrm{mL}$ for DAA). Analyte recovery was determined by comparing the peak area for each extracted analyte spiked at three concentrations to that of the corresponding standard $(n=3)$. Accuracy is expressed as a percentage of the calculated concentration divided by the nominal concentration $(n=3)$. Both intra- and inter-day precisions were indicated as the relative standard deviation (RSD, $\mathrm{n}=5$ ).

\subsection{Stability of analytes in plasma}

The stability of analytes was assessed after storage at room temperature $\left(25^{\circ} \mathrm{C}\right)$ for up to $6 \mathrm{~h}$ or three freeze-thaw cycles. The stability of the analytes with triplicate-measurements was assessed by analyzing plasma samples spiked with standards.

\subsection{Administration study}

The plasma samples used in the administration study were obtained from male Wistar rats (275-285 g) purchased from Kyudo Experimental Animal (Saga, Japan). Rats were anesthetized with $1.5 \mathrm{~g} / \mathrm{kg}$ ethyl carbamate injected intraperitoneally and a cannula for blood sampling was placed in femoral artery. For the administration study, Morinda citrifolia juice with a volume of $50 \mathrm{~mL} / \mathrm{kg}$ of body 
weight which is corresponding to $37.4 \mathrm{mg} / \mathrm{kg}$ of AA and $146 \mathrm{mg} / \mathrm{kg}$ of DAA, was administered to rats per oral. Following administration of Morinda citrifolia juice, blood samples (1 $\mathrm{mL}$ each) were drawn at various intervals between 2 and $8 \mathrm{~h}$. Plasma samples were prepared by centrifugation $\left(2000 \mathrm{~g}\right.$ ) of whole blood for $10 \mathrm{~min}$ at $4^{\circ} \mathrm{C}$. Plasma samples were stored at $-30^{\circ} \mathrm{C}$ until analysis. All animal procedures and care protocols were approved by the Nagasaki University Animal Care and Use Committee (No. 1406021153).

\section{Results and discussions}

\subsection{HPLC conditions and sample preparation}

To separate AA and DAA, HyPURITY C18 (150×4.6 $\mathrm{mm}$, i.d., $3 \mu \mathrm{m}$, ThermoFisher Scientific, Yokohama, Japan), Develosil 300 C4-HG-5 (150×2.0 mm, i.d., $5 \mu \mathrm{m}$, Nomura Chemical Co., Seto, Japan) or the ZIC ${ }^{\circledR}$-HILIC columns was examined. The analytes due to their hydrophilicity could be retained by only the ZIC ${ }^{\circledR}$-HILIC column and separated from interfering peaks. As mobile phase, a mixture of $\mathrm{CH}_{3} \mathrm{CN}$ and $0.1 \%$ formic acid aqueous solution was used. Increasing of $\mathrm{CH}_{3} \mathrm{CN}$ content in mobile phase prolonged the retention time of the analytes. By using mixture of $\mathrm{CH}_{3} \mathrm{CN}$ and $0.1 \%$ formic acid aqueous solution $(87: 13, \mathrm{v} / \mathrm{v})$ gave satisfied separation of analytes in Morinda citrifolia product. On the other hand, the separation of AA and DAA in rat plasma was achieved using the mixture of $\mathrm{CH}_{3} \mathrm{CN}, \mathrm{MeOH}$ and $0.1 \%$ formic acid aqueous solution $(70: 25: 5, \mathrm{v} / \mathrm{v} / \mathrm{v})$ (Fig. 2). The HPLC analysis completed within $25 \mathrm{~min}$ and the retention times of AA and DAA were 9.1 and $21.5 \mathrm{~min}$, respectively. A good agreement of absorption spectra of AA and DAA between standard and the appearing peaks corresponding retention time of AA and DAA was obtained.

For the determination of AA and DAA in Morinda citrifolia product and rat plasma, the sample could be applied for HPLC analysis with a simple deproteinization with $\mathrm{MeOH}$. Using $\mathrm{CH}_{3} \mathrm{CN}$ as a deproteinization agent gave the same result with that of $\mathrm{MeOH}$.

(A)

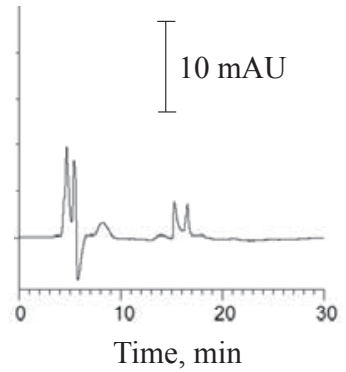



Fig. 2. Chromatograms of rat plasma (A) and that spiked with standards (B). Sample: rat plasma (A) and that spiked with 3 $\mu \mathrm{g} / \mathrm{mL}$ of AA and $15 \mu \mathrm{g} / \mathrm{mL}$ of DAA (B).

\subsection{Method validation}

The calibration curves using rat plasma spiked with standards indicated good linearity $(r \geq 0.996)$ in the range of 0.8-20 $\mu \mathrm{g} / \mathrm{mL}$ for AA and $4-100 \mu \mathrm{g} / \mathrm{mL}$ for DAA, respectively. The LODs and LOQs at an $\mathrm{S} / \mathrm{N}$ ratio of 3 and 10 for AA and DAA were $0.33,0.09 \mu \mathrm{g} / \mathrm{mL}$ and 1.1 and 0.3 , $\mu \mathrm{g} / \mathrm{mL}$, respectively. Since this is the first report to determine AA and DAA in plasma to our best knowledge, there is no data to compare the sensitivity of the method. However, the sensitivities of the proposed method with 0.06 and $0.017 \mu \mathrm{g} / \mathrm{mL}$ of $\mathrm{LOD}(=\mathrm{S} / \mathrm{N}$ ratio of 3$)$ for $\mathrm{AA}$ and DAA in Morinda citrifolia product was comparable with the conventional HPLC-PDA method [14].

The recoveries for $\mathrm{AA}$ and $\mathrm{DAA}$ were ranging from $94.9 \pm 3.5$ to $101.1 \pm 8.2 \%$ and from $95.9 \pm 4.2$ to $100.8 \pm 1.6 \%$, respectively. Other validation parameters such as accuracy, precision for intra- and inter-day measurements were summarized in Table 1. The accuracy (ranging from $95.0 \pm 3.4$ to $100.9 \pm 1.6 \%, n=3$ ), intra-day (less than $7.1 \%$, $\mathrm{n}=5$ ) and inter-day assay precisions (less than $9.8 \%, \mathrm{n}=5$ ) were acceptable.

Table 1. Accuracies and precisions for the proposed method.

\begin{tabular}{|c|c|c|c|c|}
\hline \multirow{2}{*}{ Compound } & \multirow{2}{*}{$\begin{array}{c}\text { Spiked } \\
\text { concentration } \\
(\mu \mathrm{g} / \mathrm{mL})\end{array}$} & \multirow{2}{*}{$\begin{array}{c}\text { Accuracy } \% \\
\text { Mean } \pm \text { SD } \\
(n=3)\end{array}$} & \multicolumn{2}{|c|}{$\begin{array}{c}\text { Precision } \\
\text { RSD \% }(n=5)\end{array}$} \\
\hline & & & $\begin{array}{l}\text { Intra- } \\
\text { day }\end{array}$ & $\begin{array}{l}\text { Inter- } \\
\text { day }\end{array}$ \\
\hline \multirow{3}{*}{ DAA } & 4 & $95.7 \pm 1.8$ & 7.1 & 9.8 \\
\hline & 15 & $100.9 \pm 1.6$ & 3.6 & 5.7 \\
\hline & 100 & $95.9 \pm 4.2$ & 1.7 & 2.0 \\
\hline \multirow{3}{*}{ AA } & 0.8 & $97.2 \pm 5.1$ & 6.4 & 7.5 \\
\hline & 3 & $95.0 \pm 3.4$ & 4.3 & 5.2 \\
\hline & 20 & $97.4 \pm 14.6$ & 1.6 & 2.1 \\
\hline
\end{tabular}

\subsection{Stability of analytes in plasma}

The stabilities of AA and DAA in rat plasma stored under different conditions were examined. The data was indicated as a percentage of initial concentration with triplicate-measurements. All analytes could be safely stored at room temperature for up to $6 \mathrm{~h}$ or subjected to three freeze-thaw cycles as shown in Fig. 3.

\subsection{Administration study}

Furthermore, the proposed method was applied to monitor AA and DAA concentrations after Morinda citrifolia juice administration to rat. Before administration, the concentration of AA and DAA in Morinda citrifolia juice was determined. As result, $746.6 \pm 20.4 \mu \mathrm{g} / \mathrm{mL}$ of AA 
and $2915 \pm 63 \mu \mathrm{g} / \mathrm{mL}$ of DAA were found $(\mathrm{n}=3)$. These contents in Morinda citrifolia juice agree with those of previous reports $[10,13]$.

The concentration-time profiles of the iridoids are shown in Fig. 4. The concentrations of AA and DAA in plasma were in the range of $2.38-3.67 \mu \mathrm{g} / \mathrm{mL}$ and $8.23-44.94$ $\mu \mathrm{g} / \mathrm{mL}$, respectively. The plasma concentration of AA increased slowly, reached maximum $(3.67 \mu \mathrm{g} / \mathrm{mL})$ at $4 \mathrm{~h}$ after administration, and then, decreased slowly. On the other hand, concentration behavior of DAA was similar with that of AA for up to $4 \mathrm{~h}$, but, then the concentration was increasing until $8 \mathrm{~h}$ after administration. The reasons for this phenomenon might be, 1) the one of major metabolites of AA is DAA, 2) several iridoid derivatives existing in Morinda citrifolia juice might be metabolized to DAA. In the previous report, 19 iridoid derivatives including AA and DAA in Morinda citrifolia were indicated [16]. However, the amount of DAA may be much higher than those $[10,13,16]$. To clarify this, further study to identify and determine iridoid derivatives is required.

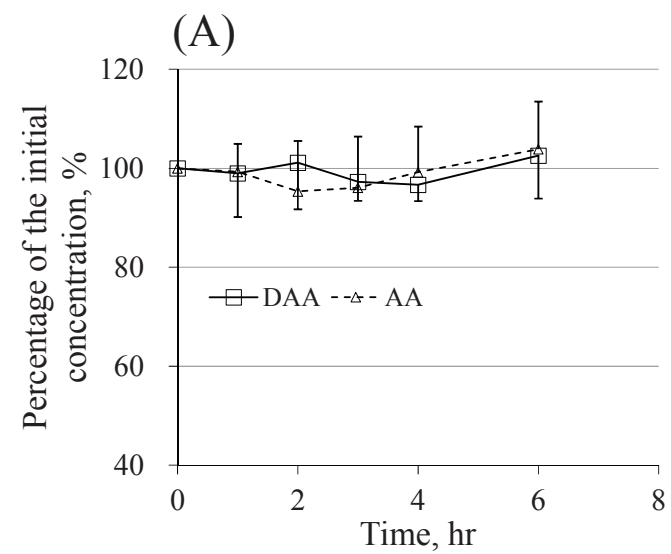

(B)

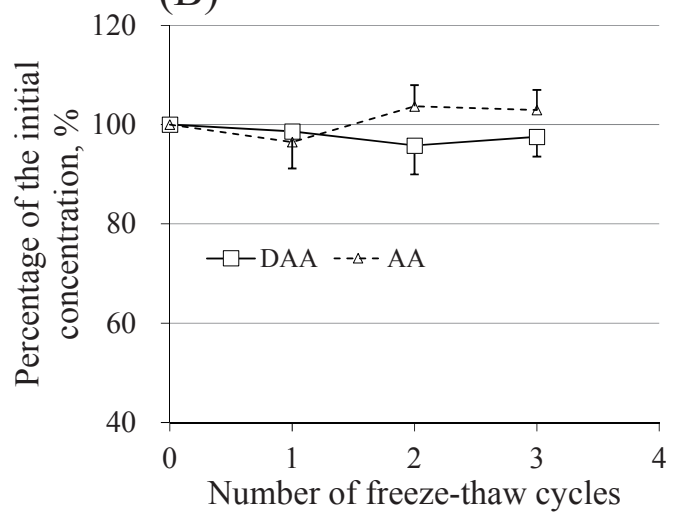

Fig. 3. Stability of AA and DAA in rat plasma. Sample: rat plasma at room temperature (A) and that in freeze-thaw cycles (B). Data was indicated as mean $+\mathrm{SD}$ (for AA) and mean SD (for DAA) SD.
On the other hand, the proposed method has several limitations: 1) only 2 derivatives (AA and DAA) could be monitored, 2) the sensitivity of the method is insufficient for human, because much higher dose of Morinda citrifolia juice compared to the recommended one by the food company is needed, 3) and the monitoring point is not enough to evaluate pharmacokinetic parameter. Therefore, it may be concluded that at this stage the proposed method is suitable for preclinical study by using experimental animals.



Fig. 4. Time courses of $\mathrm{AA}$ and DAA concentration after oral administration of Morinda citrifolia juice. Data indicates as Mean $\pm \operatorname{SE}(n=3)$.

\section{Conclusion}

The simple HPLC method with sensitivity for the determination of $\mathrm{AA}$ and DAA in rat plasma sample after administration of Morinda citrifolia juice could be established. The method has acceptable validation for bioanalysis, and thus, might be useful to clarify the contribution of iridoid derivatives for desirable health effects of Morinda citrifolia in preclinical study.

\section{Acknowledgement}

All authors appreciate Dr. T. Nishigaki (M\&K Laboratories) for his kindly supplying Morinda citrifolia product in this study.

\section{Conflict of interest}

The authors have declared no conflict of interest.

\section{References}

[1] Chan-Blanco, Y.; Vaillant, F.; Perez, M. A.; Reynes, M.; Brillouet, J.; Brat, P. J. Food Compos. Anal. 2006, 19, 645-654.

[2] Deng, S.; Palu, A. K.; West, B. J.; Su, C. X; Zhou B. N.; Jensen, J. C. J. Nat. Prod. 2007, 70, 859-862.

[3] Sang, S.; He, K.; Liu, G.; Zhu, N.; Wang, M.; Jhoo, J.; 
Zheng, Q.; Dong, Z.; Ghai, G.; Rosen, T. R.; Ho, C. Tetrahedron Lett. 2001, 42, 1823-1825.

[4] Liu, G.; Bode, A.; Ma, W.; Sang, S.; Ho, C.; Dong, Z. Cancer Res. 2001, 61, 5749-5756.

[5] Sang, S.; Liu, G.; He, K.; Zhu, N.; Dong, Z.; Zheng, Q.; Rosen, T. R.; Ho, C. Bioorgan. Med. Chem. 2003, 11, 2499-2502.

[6] Palu, K. A.; KiH. A.; West, J. B.; Deng, S.; Jarakae Jensen, C.; White, L. J. Ethnopharmacol. 2008, 115, 502-506.

[7] Ikeda, R.; Wada, M.; Nishigaki, T.; Nakashima, K. Food Chem. 2009, 113,1169-1172.

[8] Yang, J.; Paulino, R.; Janke-Stedronsky, S.; Abawi, F. Food Chem. 2007, 102, 302-308.

[9] Zin, M. Z.; Abdul-Hamid, A.; Osman, A. Food Chem. 2002, 78, 227-231.

[10] Dussossoy, E.; Brat, P.; Bony, E.; Boudard, F.; Poucheret, P.; Mertz, C.; Giaimis, J.; Michel, A. J. Ethnopharmacol. 2011, 133, 108-115.

[11] Hornick, A. C.; Myers, A.; Sadowska-Krowicka, H.; Anthony, T. C.; Woltering, A. E. Angiogenesis 2003, 6, 143-149.

[12] Wada, M. Chromatography 2011, 32, 1-7.

[13] West, J. B.; Deng, S.; Jarakae Jennsen, C. Food Res. Int. 2011, 44, 2295-2301.

[14] Deng, S.; West, J. B.; Palu, K. A.; Jarakae Jensen, C. Phytochem. Analysis 2011, 22, 26-30.

[15] Food and drug administration (FDA), Guidance for industry. Bioanalytical method validation U.S., Department of health and human services 2013, 1-25.

[16] Su, B.; Pawlus, D. A.; Jung, H.; Keller, W. J.; McLaughlim, L. J.; Kinghorn, D. A. J. Nat. Prod. 2005, 68, 592-595. 